\title{
Measurement of Serum EGF Levels, a Methodological Approach: Learning What Means “Low-/High-Concentration of EGF In Serum”. Some Clinical Implications
}

\section{Gonzalez-Perez Idania ${ }^{1 *}$, Cáceres Lavernia Haslen Hassiul ${ }^{2}$, Carr Pérez Adriana1 and León Monzón Kalet ${ }^{1}$}

${ }^{1}$ Center of Molecular Immunology, 216 Street and 15th Avenue, Atabey, Siboney, Playa, PO Box 16040, Zip Code 11600, Havana City, Cuba

${ }^{2}$ Hermanos Ameijeiras Hospital, San Lázaro Street, No. 701, Corner at Belascoaín, Havana City, Cuba

\begin{abstract}
Background: Although the contribution of platelets to the measured serum EGF levels was reported by Oka since 1983, the majority of reports in healthy donors or patients do not control clotting times during the collection of the sera. This results in a variation of the notified values, additionally to the one already caused by the functional EGF SNP of the gene, that modulates the expression of the molecule. Both issues -platelets and SNP- make the conventional stratification by absolute serum EGF levels not suitable. Within this study we evaluated serum EGF levels in a panel of 105 healthy Cuban donors, balanced by gender and age (from 18-78 years). As a result, a new stratification methodology for the comparison between individuals was proposed.

Methods: The EGF was estimated in sera collected at two different clotting times: $1 \mathrm{~h}$ and $4 \mathrm{~h}$. Comparisons between groups were carried out. The estimations, normalized through the calculation of ratios from the two measured levels $\left(r=[E G F]_{1 h} /[E G F]_{4 h}\right)$, were used for the stratification.

Results: Differences were found by age ( $4 \mathrm{~h}$, donors younger and older than 45 years, $p=0.0083$ ) and gender $(1 \mathrm{~h}, \mathrm{p}=0.0167)$, and between $1 \mathrm{~h}$ and $4 \mathrm{~h}$ levels $(\mathrm{p}<0.0001, \mathrm{n}=105)$. While 38 out of 105 individuals ranked different in $1 \mathrm{~h}$ and $4 \mathrm{~h}$ conventional stratifications, the methodology using ratios yielded a unique score for each individual.

Conclusions: The proposed methodology of stratification by ratios, in contrast to the conventional approach, allows for a proper comparison between EGF levels and individuals. Thus, it should have an impact on diseases for which the association of EGF with the illness has been established, aiding to clarify the connection of the molecule with the disease. This work might be of value to clinicians, scientists, and the healthcare community in general, conducting research regarding the role of EGF as a biomarker.
\end{abstract}

Keywords: Epidermal growth factor; Platelets; Stratification; Biomarker; Cancer

Abbreviations: EGF: Epidermal Growth Factor; sEGF: Serum Epidermal Growth Factor; EGFR: Epidermal Growth Factor Receptor; SNP: Single Nucleotide Polymorphism; AD: Alzheimer's Disease; MDD: Major Depressive Disorder

\section{Introduction}

The epidermal growth factor (EGF) was first isolated from submandibular glands of male mice [1]. Although present in serum, urine, plasma, saliva, and a variety of human tissues, the origin of serum EGF (sEGF) was unknown until 1983, when Oka and Orth published a paper describing that immunoreactive human EGF in blood was associated with platelets [2]. Since then, two theories have been considered about the primary source of EGF. Platelets do not have protein biosynthetic capability; thus it is possible that either EGF is synthesized by megakaryocytes and stored in platelets, or that it is secreted by other tissue(s) into the blood, where it is sequestered by platelets. In either case, this factor is later released into serum during the coagulation process. To our knowledge, there are few published reports about sEGF levels in healthy human donors [3-6]. In a significant part of them, the time of sera separation is either not declared or properly controlled [3], or it varies widely [5], thus affecting the reported sEGF values. Moreover, the significance of these studies is sometimes limited due to the very small number of samples included. Taking into account that platelets store EGF, which is released during the process of clot formation [2,7], and also considering the strong association between the EGF single nucleotide polymorphism (SNP) at the promoter region of the gene [8-14] and the inter-individual differences by sEGF levels, EGF was estimated in sera collected at two different times ( $1 \mathrm{~h}$ and $4 \mathrm{~h}$ ) after venipuncture. These sEGF estimates permitted assess the influence of both, platelets and EGF SNP, on the stratification of healthy individuals by sEGF levels. As a result of this analysis, a novel stratification method was proposed, which overcomes the variability observed in the conventional method of stratification. It is worth to notice that, despite this study was performed in healthy donors, its findings could be relevant for the stratification of patients by sEGF levels, in diseases for which the usefulness of this molecule as a biomarker has been previously established: in diagnosis [15-17], prognosis $[18,19]$, determination of patient's eligibility for treatment [20-22] and monitoring of the therapy in a clinical setting [17,23-26]. The results of the present study might also help to understand the kinetics of the release of EGF by the platelets, thus contributing to a better reading of the levels of this molecule in sera of healthy and sick individuals.

*Corresponding author: Idania González Pérez, Department of Systems Biology, Center of Molecular Immunology, Havana, Cuba, Tel: (537)2717933, ext 3603; E-mail: idaniagp@cim.sld.cu

Received December 30, 2016; Accepted February 11, 2017; Published February 13,2017

Citation: Idania GP, Hassiul CLH, Adriana CP, Kalet LM (2017) Measurement of Serum EGF Levels, a Methodological Approach: Learning What Means "Low-I High-Concentration of EGF In Serum". Some Clinical Implications. J Mol Biomark Diagn 8: 335. doi: 10.4172/2155-9929.1000335

Copyright: ( 2017 Idania GP, et al. This is an open-access article distributed under the terms of the Creative Commons Attribution License, which permits unrestricted use, distribution, and reproduction in any medium, provided the original author and source are credited. 


\begin{tabular}{|c|c|c|c|c|c|c|c|c|c|c|}
\hline \multirow{2}{*}{ Group } & \multirow{2}{*}{ Age (years) } & \multicolumn{2}{|c|}{ Gender $\mathbf{n}=$} & \multicolumn{3}{|c|}{ Mean Age \pm SEM (years) } & \multicolumn{3}{|c|}{ Median Age (years) } & \multirow{2}{*}{ Total } \\
\hline & & $\mathbf{W}$ & $\mathbf{M}$ & All & $\mathbf{W}$ & M & All & $\mathbf{w}$ & M & \\
\hline I & $18-45$ & 17 & 21 & $34.16 \pm 1.29$ & $31.06 \pm 1.54$ & $36.67 \pm 1.83$ & 33.50 & 31.00 & 42.00 & 38 \\
\hline II & $46-60$ & 19 & 18 & $52.32 \pm 0.66$ & $51.47 \pm 0.82$ & $53.22 \pm 1.02$ & 51.00 & 51.00 & 52.50 & 37 \\
\hline III & $61-78$ & 16 & 14 & $69.00 \pm 0.80$ & $70.50 \pm 1.09$ & $67.29 \pm 1.04$ & 68.00 & 71.00 & 68.00 & 30 \\
\hline IV & $46-78$ & 35 & 32 & $59.79 \pm 1.14$ & $60.17 \pm 1.75$ & $59.38 \pm 1.44$ & 59.00 & 59.00 & 59.50 & 67 \\
\hline Total & $18-78$ & 52 & 53 & $50.51 \pm 1.48$ & $50.65 \pm 2.30$ & $50.38 \pm 1.91$ & 51.00 & 51.00 & 51.00 & 105 \\
\hline
\end{tabular}

Table 1: Age and gender composition of different groups in the panel of healthy controls. Group IV is the sum of groups II and III. SME: standard mean error; W: women; M: man; All: the whole population.

\section{Materials and Methods}

\section{Recruitment and ethical aspects}

A panel of sera from 105 Cuban healthy volunteers, with ages between 18 and 78 years old, was prepared in partnership with the Vedado Blood Bank, the Center of Molecular Immunology (CIM) and a geriatric institution, all located in Havana, Cuba (Table 1). Based on the questionnaires, none of donors had any chronic diseases or was specially medicated. Individuals with either diabetes, or thyroid disorders, or a surgical procedure done six or fewer weeks before the moment of recruitment, were excluded. The appropriate institutional review board approved the study and a signed informed consent was obtained from all donors before the phlebotomy procedure. The sera were obtained in full compliance with the clinical and ethical practices and anonymity was guaranteed.

\section{Blood extraction and sera separation}

Two serum samples were collected from each subject, at $1 \mathrm{~h}$ and $4 \mathrm{~h}$ after phlebotomy. In the case of 11 blood bank donors, serum was also collected $24 \mathrm{~h}$ after venipuncture. The panel was balanced by gender and age (Table 1). The procedure for blood extraction and sera separation was as follows: $10 \mathrm{~mL}$ of venous blood was extracted with a $21 \mathrm{G} \times 1$ $1 / 2^{\prime}$ needle; $5 \mathrm{~mL}$ were poured into two similar corning plastic tubes, $15 \mathrm{~mL}$ capacity each, and then incubated for one hour in a bath at $37^{\circ} \mathrm{C}$. After one hour the tubes were removed from the bath; keeping one of them under incubation at room temperature (RT) for three more hours. The formed clot was separated from the inner surface using a micropipette tip, and further centrifuged at $4600 \mathrm{~g}$ for 15 minutes (5000 rpm in a Japanese Kokusan centrifuge, model H-103 N). The serum was then aspirated with a micropipette, poured in Eppendorf tubes of $1.5 \mathrm{~mL}$ to $2 \mathrm{~mL}$ capacity, and kept at RT until a second centrifugation. The second tube was centrifuged four hours after the venipuncture as described above, and then, subjected with the first tube to a second centrifugation. This second centrifugation was aimed at eliminating any remaining platelets, in order to avoid EGF release in freezing/defrosting processes. For this purpose, each Eppendorf tube was centrifuged at $10000 \mathrm{~g}$ for 12 minutes (about $12000 \mathrm{rpm}$ in a centrifuge Eppendorff MiniSpinPlus, rotor F-45-12-11 with $r_{\max }=6 \mathrm{~cm}$, $45^{\circ}$ fixed-angle). After this final centrifugation, aliquots were prepared and frozen at $-40^{\circ} \mathrm{C}$, until the moment of quantification. The sera collected at $24 \mathrm{~h}$ were similarly obtained, with a centrifugation at $24 \mathrm{~h}$ after phlebotomy.

\section{EGF measurements}

Quantification of sEGF levels was done with the UMELISA EGF $^{\circ}$ kit developed by the Center for ImmunoAssay, TecnoSUMA International S.A., Havana, Cuba [27]. It consists of a solid phase sandwich-type ultramicro ELISA (UMELISA) technique, which combines the high sensitivity of the current microELISA tests with the low cost of the used kit. It is because of the use of ultra-microvolumes of samples and reagents. The assay was performed as follows: the calibrators of the standard curve and the serum samples were both diluted in an anti-EGF biotinylated reporter monoclonal antibody, and then they were added to the reaction wells plated with a coating antiEGF monoclonal antibody. Once the complex "coating antibody-EGFreporter biotinylated antibody" was formed, a conjugate streptavidinealkaline phosphatase was added for the developing of the reaction, using 4 methylumbelliferyl phosphate as substrate. The intensities of the fluorescent signals for calibrators and assayed samples was proportional to the EGF concentrations. A linear regression model using the method of least squares was applied to log-transformed data (fluorescent signals from unknown samples and calibrators, and concentrations from calibrators) to estimate EGF concentrations in unknown samples. Each sample was tested twice in the same experiment. The intra-assays coefficients of variation were always lower than $10 \%$, in good agreement with those reported by the manufacturer of the kit [27]. It is noteworthy that, the UMELISA EGF ${ }^{\circ}$ kit exhibited similar characteristics to other commercially available assays, in terms of precision, accuracy and dynamic range [27]. Besides that, its estimations correlated very well with those obtained with the Human EGF Immunoassay Quantikine ELISA (R\&D Systems, Minneapolis, MN, USA), which is probably the most widely used kit for EGF estimations at the moment.

\section{Statistical analysis}

A contingency table was constructed aimed at finding multiple cross correlations and the possibility of dealing with confounding variables. From the computed table the most significant association was Clothing time-Gender, while the rest of cross-correlations were statistically insignificant. Besides that, the ANOVA test was consistent with the lack of further strong correlations. The $p$ value for the cross-correlation Clothing time-Gender was 0.0225. Although not statistically significant, the other lower $p$ value was 0.0959 , for the cross-correlation clotting time-age group. Thus, the analysis was explicitly focused on these both associations. The studied population was stratified by gender and age to deal with these cross-correlations in the performed analysis. Mainly Student's t-tests were used for comparisons. A two-tailed p-value $<0.05$ was considered significant. D'Agostino and Pearson omnibus normality test was used to measure the departure from normality in the distribution of data. When data was not normally distributed, the Kruskal-Wallis and Mann-Whitney tests were employed to compare the medians, instead of the means. Statistical correlations were assessed with the Pearson correlation coefficient. Graphics were built in GraphPad Prism 5 Software, Inc., version 5.03, 2009 .

\section{Results and Discussion}

Table 2 shows the estimated sEGF levels. Values were grouped by age and gender.

\section{Pattern of EGF serum levels}

The concentrations of sEGF from 105 healthy donors, measured in the sera collected at $1 \mathrm{~h}$ and $4 \mathrm{~h}$ after venipuncture, are shown in Figure 


\begin{tabular}{|c|c|c|c|c|c|c|}
\hline \multirow{2}{*}{ Gender } & \multirow{2}{*}{ Group } & \multirow{2}{*}{$n=$} & \multirow{2}{*}{$\mathbf{T}$ (hours) } & \multicolumn{2}{|c|}{ (sEGF) (pg/mL) } & \multirow{2}{*}{$\mathbf{p}$} \\
\hline & & & & Mean \pm SME & Median & \\
\hline \multirow{2}{*}{ W } & \multirow{2}{*}{$|-|||$} & \multirow{2}{*}{52} & 1 & $549.60 \pm 51.29$ & 573.50 & W vs. $M, 0.0167$ \\
\hline & & & 4 & $985.00 \pm 36.10$ & 962.40 & W vs. $M, 0.2637$ \\
\hline \multirow{2}{*}{$M$} & \multirow{2}{*}{$|-| I \mid$} & \multirow{2}{*}{53} & 1 & $398.90 \pm 35.13$ & 355.60 & \\
\hline & & & 4 & $1047.00 \pm 41.03$ & 1004.00 & \\
\hline \multirow{2}{*}{ All } & \multirow{2}{*}{$|-| I \mid$} & \multirow{2}{*}{105} & 1 & $473.50 \pm 31.70$ & 404.18 & \multirow{2}{*}{$<0.0001$} \\
\hline & & & 4 & $1016.00 \pm 27.39$ & 990.60 & \\
\hline \multirow{8}{*}{ W } & \multirow[b]{2}{*}{ I } & \multirow[b]{2}{*}{17} & 1 & $526.50 \pm 69.24$ & 644.00 & \\
\hline & & & 4 & $1018.00 \pm 59.08$ & 998.70 & $\begin{array}{l}\text { I vs. III, } 0.2483 \\
\text { I vs. IV, } 0.5248\end{array}$ \\
\hline & \multirow{2}{*}{ II } & \multirow{2}{*}{19} & 1 & $608.10 \pm 82.87$ & 587.10 & W vs. $M, 0.0047$ \\
\hline & & & 4 & $1025.00 \pm 47.63$ & 995.50 & \\
\hline & \multirow{2}{*}{ III } & \multirow{2}{*}{16} & 1 & $504.70 \pm 115.8$ & 544.20 & \\
\hline & & & 4 & $901.60 \pm 80.86$ & 822.40 & \\
\hline & \multirow{2}{*}{ IV } & \multirow{2}{*}{35} & 1 & $560.80 \pm 68.96$ & 559.90 & \\
\hline & & & 4 & $968.80 \pm 45.64$ & 941.30 & \\
\hline \multirow{8}{*}{$M$} & \multirow[b]{2}{*}{ I } & \multirow[b]{2}{*}{21} & 1 & $376.40 \pm 51.34$ & 323.00 & \\
\hline & & & 4 & $1186.00 \pm 60.98$ & 1214.00 & $\begin{array}{l}\text { I vs. III, } 0.0036 \\
\text { I vs. IV, } 0.0047\end{array}$ \\
\hline & \multirow{2}{*}{ ॥ } & \multirow{2}{*}{18} & 1 & $402.70 \pm 54.03$ & 387.20 & \\
\hline & & & 4 & $998.40 \pm 71.18$ & 951.10 & \\
\hline & II & 14 & 1 & $427.70 \pm 87.00$ & 317.80 & \\
\hline & III & 14 & 4 & $899.00 \pm 65.08$ & 838.90 & \\
\hline & IV & 32 & 1 & $413.60 \pm 47.90$ & 364.70 & \\
\hline & IV & 32 & 4 & $954.90 \pm 49.18$ & 940.60 & \\
\hline & & & 1 & $443.50 \pm 43.19$ & 390.60 & \\
\hline & I & 38 & 4 & $1111.00 \pm 44.43$ & 1060.00 & $\begin{array}{l}\text { I vs. III, } 0.0029 \\
\text { I vs. IV, } 0.0083\end{array}$ \\
\hline & 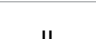 & 37 & 1 & $508.20 \pm 52.22$ & 426.60 & \\
\hline All & II & 31 & 4 & $1012.00 \pm 41.85$ & 957.10 & \\
\hline & $\mu$ & 30 & 1 & $468.70 \pm 73.03$ & 375.10 & \\
\hline & III & 00 & 4 & $900.30 \pm 51.86$ & 835.10 & \\
\hline & IV & 67 & 1 & $490.50 \pm 43.32$ & 410.70 & \\
\hline & IV & br & 4 & $962.20 \pm 33.22$ & 941.30 & \\
\hline
\end{tabular}

Table 2: Statistics of sEGF levels in the different groups of the panel. Groups by age strata: I, from 18-45 years (45 years or younger); II, from $46-60$ years; III, from 61 78 years; IV, from $46-78$ years (older than 45 years). T: time of sera collection; SME: standard mean error; W: women; M: man; All: the whole population.

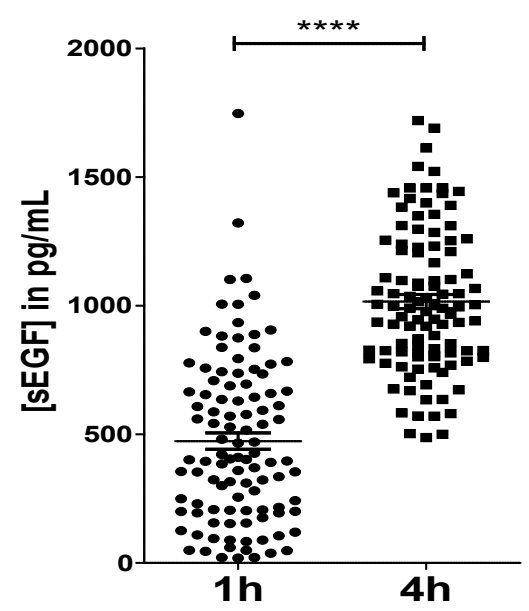

Figure 1: Scatter plot of SEGF levels from healthy Cuban donors measured in the sera collected at $1 \mathrm{~h}$ and $4 \mathrm{~h}$ after venipuncture $(n=105$, age from 18-78 years). Mean values \pm SME at $1 \mathrm{~h}$ and $4 \mathrm{~h}$ were $473.5 \mathrm{pg} / \mathrm{mL} \pm 31.70 \mathrm{pg} / \mathrm{mL}$ and $1016 \mathrm{pg} / \mathrm{mL} \pm 27.39 \mathrm{pg} / \mathrm{mL}$ respectively. ${ }^{* * * *}$ : extremely significant differences, $p<0.0001$. SME: standard mean error.
1. The observed pattern is the usual one, with extremely significant differences between mean values at $1 \mathrm{~h}$ and $4 \mathrm{~h}(\mathrm{p}<0.0001)$ (Table 2), in good agreement with previous reports [7]. However, in four donors with ages between 71 and 78 years (one man and three women), the sEGF concentrations at $4 \mathrm{~h}$ were lower than the values at $1 \mathrm{~h}$. The EGF patterns associated with these samples were named "inverted patterns". Moreover, in 6 out of the 11 sera collected $24 \mathrm{~h}$ after phlebotomy, the measured sEGF levels were very low, below the $10 \%$ of the levels in the corresponding sera separated $4 \mathrm{~h}$ after venipuncture, while in the five remaining samples, the measured values ranged between $16 \%$ and $36 \%$ of the corresponding levels at $4 \mathrm{~h}$. On the other hand, the mean sEGF value obtained at $1 \mathrm{~h}$ for the whole population ( $\mathrm{n}=105,52$ women, 53 men, 18-78 years, (Table 2), was within the range described in Taira's report $(300 \mathrm{pg} / \mathrm{mL} \pm 30 \mathrm{pg} / \mathrm{mL}, \mathrm{n}=12$, seven men, five women, 2479 years) [4]. Although the collection time of the sera is not declared in this communication, it seems to be an important variable to consider, as we just verified.

\section{Why the EGF inverted patterns?}

Since platelets are small, very compartmentalized cell fragments without nuclei, which originate from their precursors (megakaryocytes) 
in the bone marrow, the proteins they store in its organelles (EGF, among others) are mostly sequestered from the plasma. This stored content is released after platelet's activation under different stimuli or agonists, such as collagen or thrombin [28-31]. The observed deviations from the usual pattern might be explained if platelets could be able to, once all the EGF was released into the microenvironment, capture it again for its re-storage in case it was inactive, as it happens during the coagulation process. It has also been reported a similar capacity of platelets to selectively take up angiogenesis regulators and other tumor-associated biomolecules in cancer-bearing hosts [32], or ingest circulating mRNA from the tumor microenvironment [33].

The same explanation might also help to understand the inverted patterns that we have seen in some breast cancer and NSCLC patients (data not published). In these cases, they could be associated with a very high dependence of tumors on EGF, which is consistent with the very high sEGF concentrations found in these patients at $1 \mathrm{~h}$, suggesting high circulating sEGF levels (unpublished observations). In these samples, the plateau resulting from the complete EGF release by alpha granules is achieved faster than in the rest of the samples. Therefore, the platelets before the completion of the $4^{\text {th }}$ hour of clotting begin to sequester the inactive EGF in serum for its re-storage. This could explain lower sEGF concentrations at $4 \mathrm{~h}$ than those measured in their corresponding samples at $1 \mathrm{~h}$.

\section{Some correlations}

The correlation between $[\mathrm{sEGF}]_{4 \mathrm{~h}}$ and $[\mathrm{sEGF}]_{1 \mathrm{~h}}$, excluding the individuals with inverted patterns, although extremely significant $(\mathrm{p}<0.0001, \mathrm{n}=101)$ was not so strong. The Pearson correlation coefficient $\mathrm{R}$ was equal to 0.4671 , which is consistent with a linear relationship from weak to moderate. Similar correlation analyses for women $(n=49$, $\mathrm{R}=0.6614, \mathrm{p}<0.0001)$ and $\mathrm{men}(\mathrm{n}=52, \mathrm{R}=0.3623, \mathrm{p}=0.0083)$ also yielded

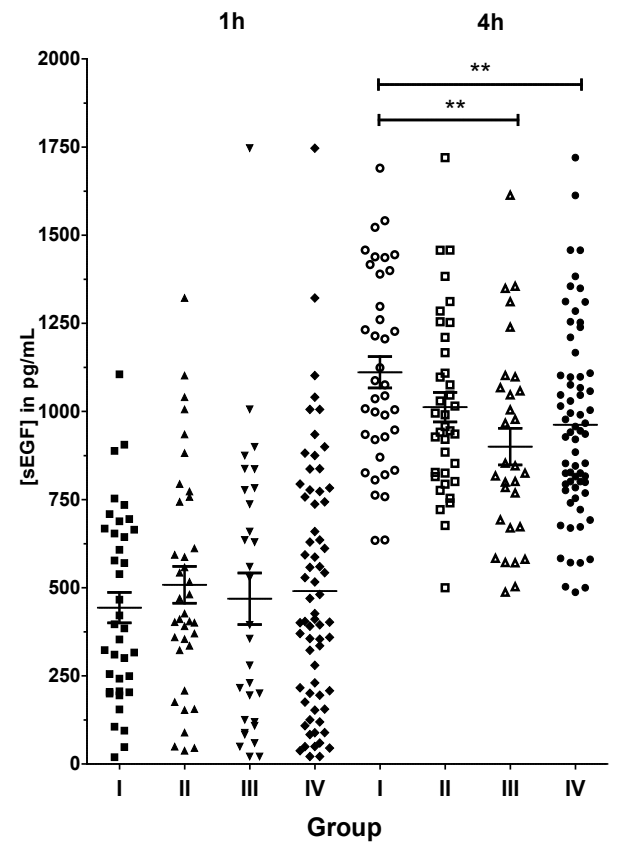

Figure 2: Comparison of sEGF levels in the sera collected $1 \mathrm{~h}$ and $4 \mathrm{~h}$ after venipuncture, in individuals from different age strata. Age groups: I (18-45 years, $\mathrm{n}=38,17$ women and 21 men); II (46-60 years, $\mathrm{n}=37,19$ women and $18 \mathrm{men}$ ); II (61-78 years, $n=30,16$ women and 14 men); IV (46-78 years, $n=67,35$ women and 32 men). Mean value \pm SME is represented for each group. SME: standard mean error; ${ }^{* *}$ : very significant differences, $p$ from 0.001 to 0.01 . significant results, with a stronger correlation for women than for men. The weakness of the obtained associations might be due primarily to the inter-individual variability, caused by the presence of the SNP in the promoter region of the EGF gene (nt61), which is functional, and hence modulates the individual's sEGF levels, no matter its health condition (see in Figure 1 the highly variable sEGF levels at $1 \mathrm{~h}$ and $4 \mathrm{~h}$ ). Secondly, the differences found by gender also caused a poor global correlation of the values. The correlation analysis between sEGF concentrations and count of platelets from 15 healthy volunteers, showed a significant relationship between them ( $1 \mathrm{~h}: \mathrm{R}=0.5762, \mathrm{p}=0.0246 ; 4 \mathrm{~h}: \mathrm{R}=0.5717$, $\mathrm{p}=0.0260$ ). This significant correlation was expected, since the EGF stored in platelets is released to the serum, contributing to the measured levels; a fact previously reported [34]. As expected, a better correlation was found for the ratios of both estimated concentrations $\mathrm{r}=[\mathrm{sEGF}]_{\mathrm{hh}} /$ $[\mathrm{sEGF}]_{4 \mathrm{~h}}[\mathrm{R}=0.5956, \mathrm{p}=0.0191]$. This is explained because $\mathrm{r}$ is in some way normalized by platelets count, due to the presence of $[\mathrm{sEGF}]_{4 \mathrm{~h}}$ as the denominator of the expression, which makes it a better variable for the comparison of individuals than absolute sEGF values.

\section{The influence of age and gender}

Table 2 shows the data organized by gender and age. Figure 2 shows the comparison between four age groups: I ( $18-45$ years, $n=38$, 17 women and $21 \mathrm{men}$ ), II (46-60 years, $\mathrm{n}=37,19$ women and $18 \mathrm{men})$, III (61-78 years, $\mathrm{n}=30,16$ women and 14 men) and IV (46-78 years, $\mathrm{n}=67,35$ women and $32 \mathrm{men})$. There were not significant differences among sEGF levels at $1 \mathrm{~h}$ between any of these groups, with $\mathrm{p}$ values that varied from 0.4606 to 0.8709 . However, we found very significant differences at $4 \mathrm{~h}$ between groups I and III, composed of young and old donors, respectively ( $p=0.0029$ ). It implies that in humans the mean EGF stock decreases with age, for the whole population (if gender is not considered in the comparison). When a similar analysis is done for women and men separately, we found the same significant differences between young and old men ( $\mathrm{p}=0.0036)$, but not for women ( $\mathrm{p}=0.2483$ ). We also found very significant differences at $4 \mathrm{~h}$ between the mean values of groups IV and I ( $\mathrm{p}=0.0083$ ) (Table 2). Looking more deeply inside these groups of individuals younger and older than 45 years, we found again differences among the men $(\mathrm{p}=0.0047)$, but not inside the group of women, when the same analysis was done $(\mathrm{p}=0.5248)$. These results suggest that differences that were found at $4 \mathrm{~h}$ between group I and groups III and IV were caused by men. Shurin et al. report a tendency of sEGF values to decrease with age [3], although they do not specify the particular behavior in women and men. However, they also report a decrease of serum levels of EGF receptor (EGFR) with age, both, in men and women, the reduction being more dramatic in the case of men. As EGF regulates the EGFR [35], this result supports the variation of sEGF levels with aging that we found for women and men. In the study of Shurin however, there is a wide variation in collection times, oscillating between $30 \mathrm{~min}$ and two hours, with the consequent variability in the estimated sEGF concentrations. Therefore, when authors group data by age only, they are probably combining for the analysis some sera that are non-comparable by clotting time. Besides that, we found significant differences between mean sEGF values for women and men in sera collected at $1 \mathrm{~h}(\mathrm{p}=0.0167)$, but not in sera separated $4 \mathrm{~h}$ after venipuncture $(\mathrm{p}=0.2637)$. Doing the same analysis by age strata, we found that although women had mean levels of sEGF at $1 \mathrm{~h}$ and $4 \mathrm{~h}$ higher than men (Table 2), the difference between them was significant only for sera collected at $1 \mathrm{~h}(\mathrm{p}=0.0047)$ in group II. These results in serum were likewise consistent with those in urine that were published by Uchihashi. The author also reports a reduction of EGF levels with age, and higher EGF levels for women ( $\mathrm{n}=102,51$ males, 51 females, from 20 to 79 years) [36]. The ratios $\mathrm{r}$ 
of sEGF levels at $1 \mathrm{~h}$ and $4 \mathrm{~h}$, multiplied by 100 , are a measure of the amount in percentages, of the circulating EGF (near the concentrations estimated in sera collected $1 \mathrm{~h}$ after phlebotomy), from the total EGF provision coming from platelets (close to concentrations assessed in sera collected $4 \mathrm{~h}$ after venipuncture). Significant differences calculated from filtered data were found $(\mathrm{p}=0.0193)$ between the mean circulating EGF (\%) values of women $(49.18 \% \pm 4.06 \%, n=49)$ and men $(37.13 \% \pm 3.09 \%, n=52)$. Measured as a percent of the total provision of EGF, women had about $12 \%$ more EGF in circulation than men. This result appears to be consistent with those reported previously for urinary EGF concentrations in humans [36]. However, when mean circulating EGF (\%) levels for women and men were compared by age strata, the differences were significant only in group I $(\mathrm{p}=0.0087)$. The values were: for women, $51.33 \mathrm{pg} / \mathrm{mL} \pm 6.16 \mathrm{pg} / \mathrm{mL}, \mathrm{n}=17$, mean and median ages of 31.06 years and 31.00 years respectively; and for men, $31.33 \mathrm{pg} / \mathrm{mL} \pm 4.15 \mathrm{pg} / \mathrm{mL}, \mathrm{n}=21$, mean and median ages of 36.67 years and 42.00 years respectively. We also calculated the differences between concentrations assessed in the sera collected at the two coagulation times $\left(\mathrm{d}=[\mathrm{sEGF}]_{4 \mathrm{~h}}-[\mathrm{sEGF}]_{1 \mathrm{~h}}\right)$. The estimated values are a measure of the EGF stored in platelets, which is completely released when the plateau is reached (near $4 \mathrm{~h}$ during the coagulation process). Individuals with inverted patterns were excluded from the analysis. The comparison of mean $\mathrm{d}$ for women and men showed very significant differences between them $(\mathrm{p}=0.0012)$, revealing that although they had similar provisions of EGF in average (from the absence of differences in values at $4 \mathrm{~h}$ ), men had stored more EGF in platelets than women, which is congruent with the fact that women had more EGF in circulation. The respective values were: $476.2 \mathrm{pg} / \mathrm{mL} \pm 36.13 \mathrm{pg} / \mathrm{mL}$, $\mathrm{n}=49$, mean and median ages of 49.14 years and 50 years; and 664.0 $\mathrm{pg} / \mathrm{mL} \pm 43.01 \mathrm{pg} / \mathrm{mL}, \mathrm{n}=52$, mean and median ages of 49.94 years and 51 years, for women and men, respectively. These mean differences for women and men compared by age strata were also significant only in group I ( $\mathrm{p}=0.0011$, women: $491.9 \mathrm{pg} / \mathrm{mL} \pm 64.05 \mathrm{pg} / \mathrm{mL}, \mathrm{n}=17$, mean and median ages of 31.06 years and 31.00 years, respectively; and men: $809.7 \mathrm{pg} / \mathrm{mL} \pm 61.66 \mathrm{pg} / \mathrm{mL}, \mathrm{n}=21$, mean and median ages of 36.67 years and 42.00 years, respectively). Therefore, the significance found

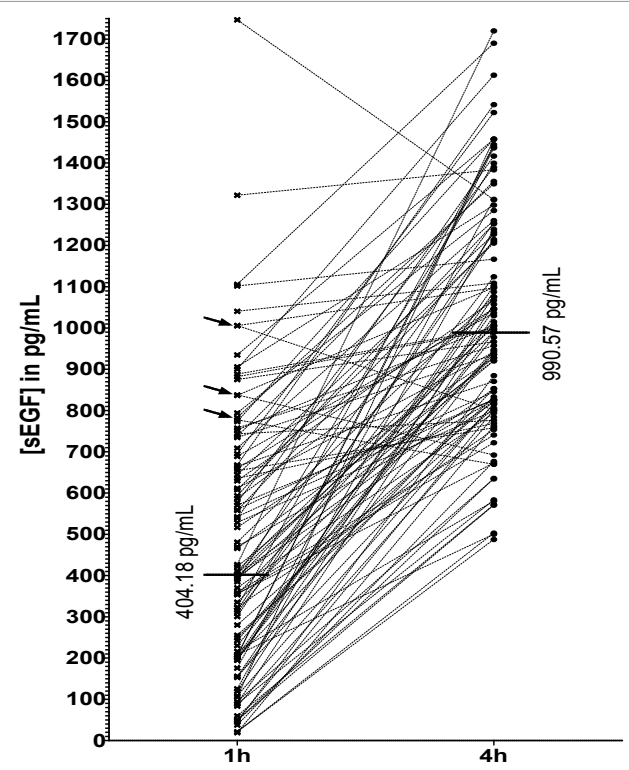

Figure 3: Variable stratification of healthy volunteers by absolute sEGF levels at $1 \mathrm{~h}$ and $4 \mathrm{~h}(\mathrm{n}=105)$. The median values for $1 \mathrm{~h}$ and $4 \mathrm{~h}$ estimations are specified: 404.18 and $990.57 \mathrm{pg} / \mathrm{mL}$ respectively. Arrows indicate three of the samples with inverted sEGF patterns in the comparison of mean $\mathrm{d}$ of women and men, was again associated with the group I of younger people from 18 to 45 years. On the other hand, while there were no differences between the groups of women, we found significant differences between groups I and II of men ( $\mathrm{p}=$ $0.0266)$. The values were: $809.7 \mathrm{pg} / \mathrm{mL} \pm 61.66 \mathrm{pg} / \mathrm{mL}, \mathrm{n}=21$, mean and median ages of 36.67 years and 42.00 years respectively, for group I; and $595.7 \mathrm{pg} / \mathrm{mL} \pm 69.59 \mathrm{pg} / \mathrm{mL}, \mathrm{n}=18$, mean and median ages of 53.22 years and 52.50 years respectively, for group II.

\section{Stratification: Absolute or relative values?}

The weak-to-moderate correlation of estimations at $4 \mathrm{~h}$ and $1 \mathrm{~h}$, the variability imposed by the clotting time (avoidable if it is properly controlled), and the inverted sEGF patterns obtained for some samples, all together hinder the stratification process by absolute sEGF levels. These issues might be a problem for the comparison of individuals through the estimated absolute values, and do not allow the identification of those with "truly high/low sEGF levels", which are actually relative concepts. Therefore, the analysis of absolute sEGF levels, for stratification purposes, might lack biological meaning in both contexts: healthy and sick individuals, because of the inherent variability of the measured levels, non-related with the previously mentioned conditions. In an attempt to stratify the studied group of healthy volunteers employing the conventional strategy by absolute sEGF levels, and taking as a cut-off value the median of the population, we found that two different arrays of data are obtained from measurements at $1 \mathrm{~h}$ and $4 \mathrm{~h}$ after phlebotomy, in which not all individuals were classified the same way (Figure 3 ). In the stratification from measurements at $4 \mathrm{~h}, 38$ out of 105 individuals $(36.19 \%)$ changed their position with respect to the median of the population, in comparison with their previous positions in the stratification from measurements at $1 \mathrm{~h}$. The nineteen that were below the median of the population at $1 \mathrm{~h}$ surpassed the $4 \mathrm{~h}$ median, and vice versa with the other nineteen that were on top. The remaining 67 individuals maintained their status below $(34 / 105,32.38 \%)$ or above $(33 / 105,31.43 \%)$ the medians in the two sets of data. In this conventional stratification, three samples with inverted sEGF patterns from the four detected were at $4 \mathrm{~h}$ below the median of the population (sEGF values: 669.39, 692.15 and $801.48 \mathrm{pg} / \mathrm{mL}$ ), although their sEGF values at $1 \mathrm{~h}$ were located very far above the median (sEGF values: 777.41, 837.74 and $1005.89 \mathrm{pg} / \mathrm{mL}$ ). See lines marked with arrows in Figure 3. On the contrary, among the nineteen that moved above the median of the population at $4 \mathrm{~h}$, there were some individuals with very low concentrations at $1 \mathrm{~h}$, which in this case classified very far below the median. Although this variability is always present, it is unnoticed when conventional stratification, involving one only estimation per individuals, is performed. In order to avoid these variations that hinder the adequate stratification by sEGF levels, the estimations were normalized by calculating the quotient $r$ from measurements at $1 \mathrm{~h}$ and $4 \mathrm{~h}\left(\mathrm{r}=[\mathrm{sEGF}]_{1 \mathrm{~h}} /[\mathrm{sEGF}]_{4 \mathrm{~h}}\right)$. The analysis of this variable $\mathrm{r}$ allows for the discrimination between "truly high/ low sEGF levels". From the comparison of r-ratios, the sEGF levels of a given person might be considered high or low depending on the fraction that represents the circulating sEGF (near the level measured at $1 \mathrm{~h}$ ), from the individual's total provision of EGF (near the sEGF level measured at $4 \mathrm{~h}$ ). Figure 4 shows the stratification by ratios $\mathrm{r}$. In this new strategy of stratification, examples of "truly low sEGF values" could be those that being above the median levels in conventional stratification when both data sets are analyzed, have ratios lower than the median of ratios of the population. The clearest example of a "truly low sEGF level" in our data set, corresponds to an individual having $[\mathrm{sEGF}]_{\mathrm{lh}}=426.57 \mathrm{pg} / \mathrm{mL}$ and $[\mathrm{sEGF}]_{4 \mathrm{~h}=} 1719.92 \mathrm{pg} / \mathrm{mL}$, with a corresponding calculated ratio equal to 0.25 (represented by the 


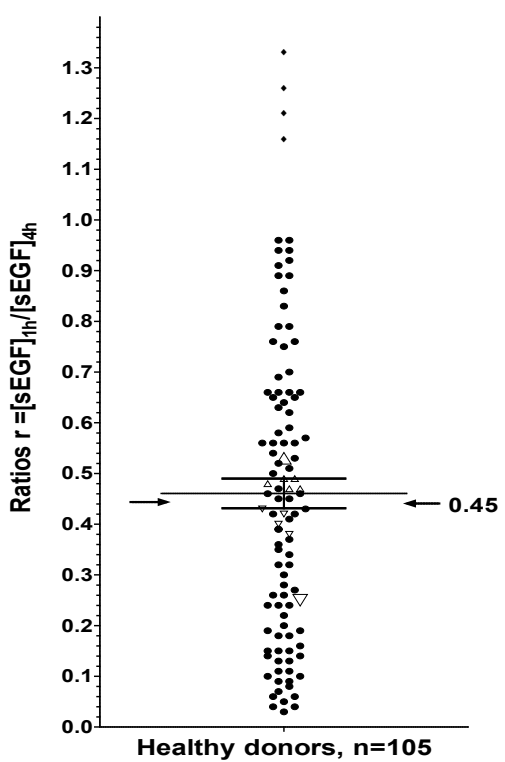

Figure 4: Stratification of donors by calculated ratios from absolute EGF levels in sera collected $1 \mathrm{~h}$ and $4 \mathrm{~h}$ after venipuncture. Mean ratio $\pm \mathrm{SME}: 0.46 \mathrm{pg} / \mathrm{mL} \pm$ $0.03 \mathrm{pg} / \mathrm{mL}$ is represented by bars. The median of ratios equal to 0.45 is indicated by arrows. Ratios corresponding to inverted sEGF patterns are represented with black diamonds $(\bullet)$. Examples of "truly high/low sEGF levels", as compared to the median of the population, are symbolized with white pointing-up $(\Delta)$ and pointing-down $(\nabla)$ triangles. SME: standard mean error.

biggest pointing-down triangle in Figure 4). Similarly, the clearest example of an individual with "truly high sEGF levels" is the one in Figure 4 that having $[\mathrm{sEGF}]_{1 \mathrm{~h}}=355.58 \mathrm{pg} / \mathrm{mL}$ and $[\mathrm{sEGF}]_{4 \mathrm{~h}}=672.72$ $\mathrm{pg} / \mathrm{mL}$, both values lower than the corresponding medians in the two data sets, has a ratio of 0.53 , which is above the median of the ratios of the analyzed population. See the biggest pointing-up triangle in Figure 4 . Wherefore, it is risky in conventional stratification, to link the ranking of individuals regarding the median value of the population, with supposed alterations of the measured levels. However, the stratification by ratios corrects this variability shortcoming of the conventional stratification. First, the inverted patterns (with inverted ratios), which correspond to "truly high sEGF values," are located in the stratification well above the rest of the population, clearly above its median value $(0.45, \mathrm{n}=105)$. Second, "truly low sEGF values" classified below the median of $\mathrm{r}$, although their values at $1 \mathrm{~h}(538.78$, $410.65,577.27,667.94 \mathrm{pg} / \mathrm{mL}$, from the examples in Figure 4 ) and $4 \mathrm{~h}$ $(1416.64,1015.19,1389.76,1541.22 \mathrm{pg} / \mathrm{mL}$, from the same examples in Figure 4) were above the respective medians. See white pointing-down triangles $(\nabla)$ in Figure 4, for the previous examples. Finally, subjects with concentrations apparently low, that were below the medians of the populations at $1 \mathrm{~h}(370.13,396.48,359.22$ and $354.31 \mathrm{pg} / \mathrm{mL})$ and also at $4 \mathrm{~h}(793.94,820.53,740.57,721.7 \mathrm{pg} / \mathrm{mL})$, but which are "truly high sEGF values" considering the fractions that represent the concentrations at $1 \mathrm{~h}$ with respect to the concentrations at $4 \mathrm{~h}$, were also located above the median of ratios (see white pointing-up triangles $(\Delta)$ in Figure 4). The estimation of ratios from the sEGF levels at $1 \mathrm{~h}$ and $4 \mathrm{~h}$ and its stratification, is the approach we propose to normalize the estimations and achieve a proper comparison between individuals, muting the variability caused by the polymorphism of the gene and the contribution of platelets during coagulation. In this new strategy of stratification, the concepts of "low sEGF value" and "high sEGF value" will depend on the fraction that represents the circulating EGF values (near the levels measured at $1 \mathrm{~h}$ ), from the total provision of EGF (near the levels measured at $4 \mathrm{~h}$ ). This interpretation adds biological meaning to the estimations of sEGF levels; the analysis of ratios gives more information about the availability (circulation) or presumed accessibility or activity of EGF (especially in the case of patients) than the comparison of those highly variable absolute sEGF levels.

\section{Clinical implications of the findings}

Based on the stratification results of the studied healthy population, employing both methodologies: the conventional and the new one proposed, by mean of ratios $r$, and also considering the calculated ratios for 25 NSCLC patients in a parallel study (unpublished observations), we conclude that $r=[\mathrm{sEGF}]_{1 \mathrm{~h}} /[\mathrm{sEGF}]_{4 \mathrm{~h}}$ is a more suitable variable for stratification than absolute serum EGF levels, because it is able to differentiate between "truly low" and "truly high" sEGF values, as well as between healthy and sick individuals (data not published).

The proposed strategy of stratification should have an impact on diseases for which the association of EGF with the illness has been more or less established. Also in this context, the comparison of sEGF values with the aid of the variable $r$ might help to clarify the connection of the molecule with the disease. Widely expressed in the body, this protein plays a fundamental role in development, tissue regeneration and ion transport, which occur either by the molecule itself or synergistically with other members of EGF family, through the EGF/EGFR axis. The dysregulation of this axis has been particularly linked to cancer development, and also to several other diseases and their pathogenesis. Therefore, in addition to a number of epithelial cancers [8-10,16-19,23$25,31]$, some other diseases might also be benefited with the proposed strategy of stratification.

Although further studies should be done, in order to clarify the exact contribution of EGF to atherosclerosis, some works support the possible link of this factor with the pathogenesis of this vascular disease. The EGF stimulates growth of vascular smooth muscle cells, a phenomenon important in atherosclerosis [2,37], elicits both chemotactic and mitogenic responses in macrophages, and additionally upregulates the EGFR, which suggests an exceptionally important role in atherogenesis, and perhaps other chronic inflammatory processes [38]. Although some reports are contradictory, in healthy young population high sEGF levels have been associated with elevated diastolic blood pressure, as well as increased vessel stiffness (a marker for coronary artery disease), providing also a possible functional link between EGF and the cardiovascular system $[39,40]$.

On the other hand, it is also known that EGF is involved in development of the brain and its neurons. Present in several regions of the adult or developing brain it enhances the differentiation, maturation, and survival of a variety of neurons, while the EGFR signaling has been highlighted directly or indirectly in a spectrum of several neurometabolic and neurodegenerative conditions such as diabetes and Alzheimer's disease (AD), and some neurological disorders as depression, autism, and schizophrenia, among others. Decreased salivary EGF levels are reported in diabetic patients, compared to controls [41]. Considering that EGF levels in serum and saliva correlate very well [42], diminished sEGF levels are also expected in diabetic people. In $\mathrm{AD}$ no single biomarker has been identified in blood, despite an intense search over the last decade. Though EGF has been considered as a possible biomarker, the results from plasma EGF levels have been conflicting [43]. One study reports decreased concentrations of EGF, while another declared increased plasma levels in patients compared to controls $[44,45]$. Decreased EGF 
levels in platelets of $\mathrm{AD}$ patients have been also reported, indicating an enhanced release of platelet EGF into plasma [46,47]. It has been also stated that plasmatic levels of EGF are significantly reduced in patients with major depressive disorder (MDD), a common psychiatric disease whose precise mechanism is poorly understood [48]. Based on the neurotrophic hypothesis, the authors conclude that EGF levels in plasma might be a useful biomarker for the early diagnosis, prognosis and treatment of major psychiatric disorders. Other studies have found significant decreased sEGF levels in subjects with high-functioning autism, compared to those in normal control subjects [49], which suggest that decreased levels of sEGF might be implicated in the pathophysiology of this disease. Finally, the low incidence of cancer in schizophrenia is one of the interesting puzzles in psychiatric field over decades. Known to be involved in cognitive function, the role of EGF in schizophrenia has not been elucidated. Futamura suggests an abnormal EGF production in central and peripheral nervous system of patients with schizophrenia [15]. In the contradictory results of some of these reports also lies the methodological problem in the estimations of sEGF values. The application of the proposed method for quantification and stratification of the estimated concentrations of EGF in serum, might contribute to a better reading of the levels of this molecule in the context of these diseases. We conclude that this work might be of value to clinicians, scientists, and professionals in the healthcare community, conducting research related with the role of EGF as a biomarker. This knowledge could also be useful to professionals working with other growth factors equally stored in platelets (TGFbeta, PDGF, VEGF, to mention only some examples), for which the kinetics release could be very alike to the one described for EGF, with an impact in their measurements and very similar implications in the clinic.

\section{Acknowledgements}

The authors wish to thanks Nurse Belkis Felicia Escobar, physician Milagros Carmona Forcade, and colleagues Amnely González Morera, Zuyén González Castillo and Esperanza Hechevarría Ruíz, for their valuable assistance in procedures of phlebotomy. The author IGP wants to thank David Quesada from St. Thomas University, USA, for the valuable discussions and proof reading of the manuscript.

\section{References}

1. Cohen S (1962) Isolation of a mouse submaxillary gland protein accelerating incisor eruption and eyelid opening in the new-born animal. J Biol Chem 237: $1555-1562$.

2. Oka Y, Orth DN (1983) Human plasma epidermal growth factor/betaurogastrone is associated with blood platelets. J Clin Invest 72: 249-259.

3. Shurin G, Zoya R, Gurkamal S, Irina L, Michael R, et al. (2007) Dynamic alteration of soluble serum biomarkers in healthy aging. Cytokine 39: 123-129.

4. Taira T, Yoshimura A, lizuka K, Iwasaki S, Ideura T, et al. (1993) Urinary epidermal growth factor levels in patients with acute renal failure. Am J Kidney Dis 22: 656-661.

5. Joh T, Itoh M, Katsumi K (1986) Physiological concentrations of human epidermal growth factor in biological fluids: use of a sensitive enzyme immunoassay. Clin Chim Acta 158: 81-90.

6. Pesonen K, Viinikka L, Myllyla G, Kiuru J, Perheentupa J (1989) Characterization of material with epidermal growth factor immunoreactivity in human serum and platelets. J Clin Endocrinol Metab 68: 486-491.

7. Savage AP, Chatterjee VK, Gregory H, Bloom SR (1986) Epidermal growth factor in blood. Regul Pep 16: 199-206.

8. Tanabe KK, Lemoine A, Finkelstein DM, Kawasaki H, Fujii T, et al. (2008) Epidermal growth factor gene functional polymorphism and the risk of hepatocellular carcinoma in patients with cirrhosis. JAMA 299: 53-60.

9. Teixeira AL, Ribeiro R, Cardoso D, Pinto D, Lobo F, et al. (2008) Genetic Polymorphismin EGF is associated with prostate cancer aggressiveness and progression-free interval in androgen blockade treated patients. Clin Cancer Res 14: 3367-3371.
10. Araújo AP, Ribeiro R, Pereira D, Pinto D, Sousa B, et al. (2009) Ovarian Cancer and genetic susceptibility: Association of A61G Polymorphism in the EGF gene. Exp Biol Med 234: 241-245.

11. Price PM, Megyesi J, Saggi S, Safirstein RL (1995) Regulation of transcription by the rat EGF gene promoter in normal and ischemic murine kidney cells. Am J Physiol 268: 664-670.

12. Xu W, Li Y, Wang X, Chen B, Liu S, et al. (2010) Association between EGF promoter polymorphisms and cancer risk: A meta-analysis. Med Oncol 27 1389-1397.

13. Li TF, Ren KW, Liu PF (2012) Meta-analysis of epidermal growth factor polymorphisms and cancer risk: Involving 9,779 cases and 15,932 controls. DNA Cell Biol 31: 568-574.

14. Yoshiya S, Fujimoto Y, Bekki Y, Konishi H, Yamashita Y, et al. (2014) Impact of epidermal growth factor single-nucleotide polymorphism on recurrence of hepatocellular carcinoma after hepatectomy in patients with chronic hepatitis C virus infection. Canc Sci 105: 646-650.

15. Futamura T, Kakita A, Tohmi M, Sotoyama $H$, Takahashi $H$ (2003) Neonatal perturbation of neurotrophic signaling results in abnormal sensorimotor gating and social interaction in adults: Implication for epidermal growth factor in cognitive development. Mol Psychiatry 8: 19-29.

16. Blanco-Prieto S, Vázquez-Iglesias L, Rodríguez-Girondo M, Barcia-Castro L, Fernández-Villar A (2015) serum calprotectin, CD26 and EGF to establish a panel for the diagnosis of lung cancer. PLoS ONE.

17. Bello L (1996) Urinary epidermal growth factor (EGF) levels and epiderma growth factor receptor (EGF-R) expression in human cerebral tumors. Clinical considerations. J Neurosurg Sci 40: 167-182.

18. Wataru Y, Jotaro H, Hiroshi Y, Hiroshi N, Tsushi O (1988) Interaction between epidermal growth factor and its receptor in progression of human gastric carcinoma. Int J Cancer 41: 211-217.

19. Bracher A, Soler A, Tauber S, Fink A, Steiner A (2013) epidermal growth factor facilitates melanoma lymph node metastasis by influencing tumor lymphangiogenesis. J Invest Dermatol 133: 230-238.

20. Neninger E, de la Torre A, Osorio M, Catala' M, Bravo I (2008) Phase II randomized controlled trial of an epidermal growth factor vaccine in advanced non-small-cell lung cancer. J Clin Oncol 26: 1452-1458.

21. Camilo P (2014) Phase III Clinical Trial: Survival of advanced NSCLC patients receiving maintenance therapy with CIMAvax-EGF, with serum EGF levels bigger than $850 \mathrm{pg} / \mathrm{mL}$ after first line chemotherapy. Report to center for the state control of drugs, equipment and medical devices, Cuba.

22. Yang L, Wang L, Zhang $Y$ (2016) Immunotherapy for lung cancer: Advances and prospects. Am J Clin Exp Immunol 5: 1-20.

23. García B, Neninger E, de la Torre A, Leonard I, Martínez R (2008) Effective inhibition of the epidermal growth factor/epidermal growth factor receptor binding by anti-epidermal growth factor antibodies is related to better survival in advanced non-small-cell lung cancer patients treated with the epidermal growth factor cancer vaccine. Clin Canc Res 14: 840-846.

24. Crombet T, Neninger E, Gonzalez J, Camilo P, García B (2013) EGF-based cancer vaccine: Optimizing predictive and surrogate biomarkers. J Clin Oncol.

25. Roche HL (2010) Method for predicting the response to a treatment.

26. Ridge Diagnostics (2013) Biomarkers for monitoring treatment of neuropsychiatric diseases.

27. Castells E, Del Valle R, González E, Melchor A, Pérez P, et al. (2016) An enzyme immunoassay for determining epidermal growth factor (EGF) in human serum samples using an ultra microanalytical system. J Immunoassay Immunochem,

28. Salem HH, Koutts J, Handley C, Van Der Weyden MB et al. (1981) The aggregation of human platelets by ascitic fluid: A possible mechanism for disseminated intravascular coagulation complicating LeVeen shunts. Am J Hematol 11: 153-157.

29. Jurasz P, Alonso-Escolano D, Radomski MW (2004) Platelet-cancer interactions: Mechanisms and pharmacology of tumour cell-induced platelet aggregation. Br J Pharmacol 143: 819-826.

30. Horstman LL, Jy W, Ahn YS, Zivadinov R, Maghzi A, et al. (2010) Role of platelets in neuroinflammation: A wide-angle perspective. Neuroinflamm 7: 10. 
Citation: Idania GP, Hassiul CLH, Adriana CP, Kalet LM (2017) Measurement of Serum EGF Levels, a Methodological Approach: Learning What Means "Low-/High-Concentration of EGF In Serum". Some Clinical Implications. J Mol Biomark Diagn 8: 335. doi: 10.4172/2155-9929.1000335

Page 8 of 8

31. Stegner D, Dütting S, Nieswandt B (2014) Mechanistic explanation for platelet contribution to cancer metastasis. Thromb Res 133: 149-157.

32. Klement GL, Yip T, Cassiola F (2009) Platelets actively sequester angiogenesis regulators. Blood 113: 2835-2842.

33. Best MG, Sol N, Kooi I, Tannous BA, Wesseling P, et al. (2015) RNA-Seq of tumor-educated platelets enables blood-based pan-cancer, multiclass, and molecular pathway cancer diagnostics. Cancer Cell 28: 1-11.

34. Lev-Ran A, Hwang DL, Snyder DS (1990) Human serum and plasma have different sources of epidermal growth factor. Am J Physiol 259: 545-548.

35. Clark A, Ishii S, Richert N, Merlino G, Pastan I (1985) Epidermal growth factor regulates the expression of its own receptor. PNAS 82: 8374-8378.

36. Uchihashi M, Hirata Y, Fujita T, Matsukura S (1982) Age-related decrease of urinary excretion of human epidermal growth factor (hEGF). Life Sci 31 : 679-683.

37. Dreux A, Lamb D, Modjtahedi H, Ferns G (2006) The epidermal growth factor receptors and their family of ligands: Their putative role in atherogenesis. Atherosclerosis 186: $38-53$.

38. Lamb D, Modjtahedi H, Plant N, Ferns G (2004) EGF mediates monocyte chemotaxis and macrophage proliferation and EGF receptor is expressed in atherosclerotic plaques. Atherosclerosis 176: 21-26.

39. Lundstama U, Hägga U, Sverrisdottira Y, Svenssonc L, Gan L (2007) Epiderma growth factor levels are related to diastolic blood pressure and carotid artery stiffness. Scand Cardiovasc J 41: 308-312.

40. Berrahmoune H, Lamont J, Herbeth B, Lambert D, Masson C (2009) Association between EGF and lipid concentrations: $A$ benefit role in the atherosclerotic process? Clin Chim Acta 402: 196-198.

41. Oxford G, Tayaria L, Barfoot M, Peck A, Tanaka Y (2000) Salivary EGF levels reduced in diabetic patients. J Diabetes Its Complicat 14: 140-145.

42. Hayashi T, Sakamoto S (1988) Radioimmunoassay of human epidermal growth factor-hEGF levels in human body fluids. J Pharmacobio-Dyn 11: 146-151.

43. Humpel C, Hochstrasser T (2011) Cerebrospinal fluid and blood biomarkers in AD. World J Psychiatr 1: 8-18.

44. Ray S, Britschgi M, Herbert C, Takeda-Uchimura Y, Boxer A (2007) Classification and prediction of clinical Alzheimer's diagnosis based on plasma signaling proteins. Nat Med 13: 1359-1362.

45. Marksteiner J, Kemmler G, Weiss E, Knaus G, Ullrich C (2011) Five out of 16 plasma signaling proteins are enhanced in plasma of patients with mild cognitive impairment and Alzheimer's disease. Neurobiol Aging 32: 539-540.

46. Hochstrasser T, Ehrlich D, Marksteiner J, Sperner-Unterweger B, Humpel C (2012) Matrix metalloproteinase-2 and epidermal growth factor are decreased in platelets of $A D$. Curr Alzheimer Res 9: 982-989.

47. Plagg B, Marksteiner J (2015) Platelet dysfunction in hypercholesterolemia mice, two Alzheimer's disease mouse models and in human patients with Alzheimer's disease. Biogerontology 16: 543-558.

48. Tian W, Zhang J, Zhang K, Yang H, Sun Y (2012) A study of the functional significance of epidermal growth factor in major depressive disorder. Psyc Genet 22: 161-167.

49. Suzuki K, Hashimoto K, Iwata Y, Nakamura K, Tsujii M, et al. (2007) Decreased serum levels of epidermal growth factor in adult subjects with high-functioning autism. Biol Psychiatry 62: 267-269. 